\title{
C-4 Routes to Methyl Methacrylate: A Sustainable and Environmental Benign Process
}

\author{
Lai Sin Yuan* \\ School of Energy and Chemical Engineering, Xiamen University Malaysia, Selangor Darul Ehsan, 43900, Malaysia; College of Chemistry and Chemical \\ Engineering, Xiamen University, Xiamen, 361005, China
}

${ }^{\star}$ Corresponding author: Lai Sin Yuan, School of Energy and Chemical Engineering, Xiamen University Malaysia, Selangor Darul Ehsan, 43900, Malaysia; Email: sinyuan.lai@xmu.edu.my

Received: August 10, 2021; Accepted: August 20, 2021; Published: September 03, 2021

The polymerization process using methyl methacrylate (MMA) has been intensively manufactured owing to poly(methyl methacrylate) (PMMA) is a synthetic thermoplastic with high durability, heat resistance, chemical resistance, light transmission, UV resistant, shattering resistance, optical clarity, high scratch resistance, and so forth. Due to these excellent features, PMMA is patented with trademarks, inclusive of Plexiglas ${ }^{\oplus}$, Acrylite ${ }^{\oplus}$, Parapet ${ }^{\oplus}$, Perspex ${ }^{\oplus}$, Altuglas ${ }^{\oplus}$, etc. Its incredible role in our daily life is indispensable as we could find PMMA everywhere, such as solar panels, window profiles, lightning, car windows, lights cover, Smartphone screen displays, dental cavity fillings, and so on. Methyl methacrylate (MMA) is the crucial monomer of PMMA, which is also widely used in coatings, paints, adhesives, packaging, sealants, floor polishes, etc. [1]. Despite amid the outbreak of coronavirus in 2019, the market demand of MMA is estimated to grow in coming years. The MMA annual growth rate of a market report has forecasted 3.9\% CAGR till 2028 [2] while another report has projected a higher growth rate, $4.3 \%$ CAGR, in year 2020-2027 [3]. Apparently, MMA is an ignorable material found in our daily routines, especially in automotive, coatings and paintings. Several industrial processes have been engaged to produce a series precursors of MMA, including methacrolein (MAL) and methacrylic acid (MAA) through ACH process, C-2, C-3, and C-4 methods $[4,5]$. $\mathrm{ACH}$ process is economically attractive but it is restraining from the usage of hazardous $\mathrm{HCN}$ reactant and co-production of toxic $\mathrm{NH}_{4} \mathrm{HSO}_{4}$. C-2 process generally presents high selectivity but low one-pass conversion, high preparation costs, and low yield caused by MMA hydrolysis to MAA and methanol; C-3 process suffers from limited starting material (propyne) although it gives high yield of MMA through one-step conversion. The aforementioned literature studies are the pros and cons of $\mathrm{ACH}, \mathrm{C}-2$, and C-3 processes in the MAL, MAA or MMA production [5].

On the other hand, C-4 hydrocarbons which comprised of isobutane, isobutene, tert-butyl alcohol, methacrolein (MAL) or 2-methyl-1, 3-propanediol, are the byproducts obtained from petroleum refinery process. Thus, these chemicals are considerably high availability and less hazardous compared to the other methods mentioned. The obtained C-4 materials act as the main feedstocks in chemical industry owing to their intermediates and products have high-commercialised values. This process is also more industrialized practical because the feedstock could produce higher yield of MMA with lower capital costs. By valorizing the byproducts from petroleum to value-added intermediates or products, C- 4 process is also in line with Sustainable Global Development, Goal No. 12 Responsible Consumption and Production. To further promote the production of MMA, engineering of appropriate structural catalysts should be studied. There are diverse catalysts used to enhance the conversion, selectivity and yield towards MAL, MAA or/and MMA, such as vanadium pyrophosphate [6], CsFeCoBiMnMoO ${ }_{x}$ [7], $\mathrm{Pd}-\mathrm{Pb} / \gamma-\mathrm{Al}_{2} \mathrm{O}_{3}$ [8], Bi-doped-styrene-divinyl benzene copolymer (SDB) [9], $\mathrm{Cu}$ - and Fe-doped $\mathrm{CsH}_{3} \mathrm{PMo}_{11} \mathrm{VO}_{40}[10]$, NiAu single atom alloys and so forth [11]. Heteropolyacid is revealed as one of the efficient mixed metal oxides in the oxidation of light alkanes due to its dual functionality, i.e. acidity and oxidative properties. The advanced materials, such as layered double hydroxide (LDH), metal-organic framework (MOF), and etc, are potential to be functionalized with metal oxide-based materials to give synergistic effects.

Additionally, a cascade pathway from C-4 to MMA should be advocated too. Since both MAL and MAA are the intermediates to produce the desired MMA, therefore isobutane or isobutene conversion to MAL and MAA are vastly reported. Undeniably, efforts extensively focus on discontinuous processes to MAL or MAA: the oxidative dehydrogenation of isobutane or/and isobutene to MAL [12-15], oxidative dehydrogenation of isobutane to MAA [16,17], and MAL oxidation to MAA [18-23]. In recent years, it is worth noting that the cascade oxidative esterification of MAL to MMA has been investigated $[9,11,24,25]$, nonetheless, on-going studies are still necessary. Directing the discontinuous process to cascade one-step synthetic route is an urge due to the process simplicity and reduced byproducts. This will be prompting energy- and cost-saving with the aim to create a sustainable, eco-friendly environment and economically viable communities.

In short, this research has grown rapidly with possessing great potential in the field of industrial catalysis, which great strides in synthetic transformation process and catalysts engineering. This is making towards environmental cleanliness and sustainable process. 


\section{Acknowledgements}

The work is supported by Ministry of Higher Education (MOHE) through the Fundamental Research Grant Scheme (FRGS/1/2019/ TK02/XMU/03/1), Hengyuan International Sdn. Bhd. (grant number: EENG/0003) and Xiamen University Malaysia Research Fund (grant number: XMUMRF/2019-C4/IENG/0019 and XMUMRF/2020-C5/ IENG/0029).

\section{References}

1. Kato Y, Nitta S, Shimazu S, Kurashina M, Katoh M, et al. (2019) Effect of introduction of trace amount of chromium species in improving catalytic performance of MCM48 in oxidative dehydrogenation of isobutane. Journal of Chemical Engineering of Japan 52: 99-105.

2. Global market study on methyl methacrylate (MMA) - Increasing application in PMMA production to account for significant revenue generation opportunities (2019).

3. Methyl methacrylate (MMA) - Global market trajectory \& analytics (2021).

4. Nagai K (2001) New developments in the production of methyl methacrylate. Applied Catalysis A: General 221: 367-377.

5. Mahboub MJD, Dubois JL, Cavani F, Rostamizadeh M, Patience GS (2018) Catalysis for the synthesis of methacrylic acid and methyl methacrylate. Chemical Society Review 47: 7703-7738.

6. Guan J, Xu H, Jing S, Wu S, Ma Y, et al. (2008) Selective oxidation of isobutane and isobutene over vanadium phosphorus oxides. Catalysis Communications 10: 276-280.

7. Peng Z, Yu C, Cai T, Deng Q (2004) Selective oxidation of isobutene over CsFeCoBiMnMoOx mixed oxide catalyst. Journal of Natural Gas Chemistry 13: 172-176.

8. Diao Y, Yang P, Yan R, Jiang L, Wang L, et al. (2013) Deactivation and regeneration of the supported bimetallic $\mathrm{Pd}-\mathrm{Pb}$ catalyst in direct oxidative esterification of methacrolein with methanol. Applied Catalysis B: Environmental 142: 329-336.

9. Wang B, Li H, Zhu J, Sun W, Chen S (2013) Preparation and characterization of mono-/multi-metallic hydrophobic catalysts for the oxidative esterification of methacrolein to methyl methacrylate. Journal of Molecular Catalysis A: Chemical 379: 322-326.

10. Zhang H, Yan R, Yang L, Diao Y, Wang L (2013) Investigation of Cu- and Fe-doped $\mathrm{CsH}_{3} \mathrm{PMo}_{11} \mathrm{VO}_{40}$ heteropoly compounds for the selective oxidation of methacrolein to methacrylic acid. Industrial \& Engineering Chemistry Research 52: 4484-4490.

11. Trimpalis A, Giannakakis G, Cao S, Flytzani-Stephanopoulos M (2020) NiAu single atom alloys for the selective oxidation of methacrolein with methanol to methyl methacrylate. Catalysis Today 355: 804-814.

12. Weber D, Weidler P, Kraushaar-Czarnetzki B (2017) Partial oxidation of isobutane and isobutene to methacrolein over a novel $\mathrm{Mo}-\mathrm{V}-\mathrm{Nb}(-\mathrm{Te})$ mixed oxide catalyst. Topics in Catalysis 60: 1401-1407.

13. Zhai Z, Wang X, Licht R, Bell AT (2015) Selective oxidation and oxidative dehydrogenation of hydrocarbons on bismuth vanadium molybdenum oxide. Journal of Catalysis 325: 87-100.

14. Jia MJ, Valenzuela RX, Amorós P, Beltrán-Porter D, El-Haskouri J, et al. (2004) Direct oxidation of isobutane to methacrolein over V-MCM-41 catalysts. Catalysis Today 91-92: 43-47.

15. Guan J, Song K, Xu H, Wang Z, Ma Y, et al. (2009) Oxidation of isobutane and isobutene to methacrolein over hydrothermally synthesized Mo- $\mathrm{V}-\mathrm{Te}-\mathrm{O}$ mixed oxide catalysts. Catalysis Communications 10: 528-532.

16. Jing F, Katryniok B, Dumeignil F, Bordes-Richard E, Paul S (2014) Catalytic selective oxidation of isobutane to methacrylic acid on supported $\left(\mathrm{NH}_{4}\right)_{3} \mathrm{HPMo}_{11} \mathrm{VO}_{40}$ catalysts. Journal of Catalysis 309: 121-135.

17. Capua AD, Dubois JL, Fournier M (2007) Fine analysis of by-products of the selective oxidation of isobutane into methacrolein and methacrylic acid over MoV-P catalyst. Journal of Molecular Catalysis A: Chemical 263: 62-69.

18. Yasuda S, Iwakura A, Hirata J, Kanno M, Ninomiya W, et al. (2019) Strong Brønsted acid-modified chromium oxide as an efficient catalyst for the selective oxidation of methacrolein to methacrylic acid. Catalysis Communications 125: 43-47.
19. Zhou L, Sun Y, Li B, Zhengjie Li, Zhang Z, et al. (2019) Selective oxidation of methacrolein to methacrylic acid on carbon catalysts. Catalysis Communications 126 : 44-49.

20. Cao YL, Wang L, Xu BH, Zhang SJ (2018) The Chitin/Keggin-type heteropolyacid hybrid microspheres as catalyst for oxidation of methacrolein to methacrylic acid. Chemical Engineering Journal 334: 1657-1667.

21. Zhou L, Wang L, Diao Y, Yan R, Zhang S (2017) Cesium salts supported heteropoly acid for oxidation of methacrolein to methacrylic acid. Molecular Catalysis 433: 153161 .

22. Zheng Y, Zhang H, Wang L, Zhang S, Wang S (2016) Transition metal-doped heteropoly catalysts for the selective oxidation of methacrolein to methacrylic acid. Frontiers of Chemical Science and Engineering 10: 139-146.

23. Zhou L, Wang L, Wang H, Cao Y, Yan R, et al. (2016) Silica supported heteropoly catalysts for oxidation of methacrolein to methacrylic acid. Journal of Thermodynamic and Catalysis 7: 1000176.

24. Guan Y, Ma H, Chen W, Li M, Qian G, et al. (2020) Methyl methacrylate synthesis: Thermodynamic analysis for oxidative esterification of methacrolein and aldol condensation of methyl acetate. Industrial \& Engineering Chemistry Research 59: 17408-17416.

25. Li H, Tan Y, Chen X, Yang W, Huang C, et al. (2021) Efficient synthesis of methyl methacrylate by one step oxidative esterification over $\mathrm{Zn}$-Al-mixed oxides supported gold nanocatalysts. Catalysts 11: 162.

\section{Citation:}

Yuan LS (2021) C-4 Routes to Methyl Methacrylate: A Sustainable and Environmental Benign Process. Nanotechnol Adv Mater Sci Volume 4(1): 1-2. 